\title{
Research and Analysis on the structure model of College Teachers' teaching ability
}

\author{
Liman Zhao ${ }^{1, \text { a }}$, Xiaoyun Chen ${ }^{1, b}$ \\ ${ }^{1}$ Jiangxi Science \& Technology Normal University, Nanchang, Jiangxi, 330013, China \\ alimzhao@126.com, b40905438@qq.com
}

Keywords: University teachers; teaching ability; structure model; characteristics; analysis

\begin{abstract}
Because of the continuous development of education in our country, the teacher's teaching ability has been improved. The teaching ability of teachers is an important factor for the construction and development of colleges and universities. In the era of rapid development of information technology, college education has become an indispensable part of social development. And the teaching level of teachers has a great influence on the quality of teaching. It is the foundation of steady development and training high quality talents in Colleges and universities. This paper will combine the characteristics of the teaching ability of college teachers to explore the construction of the structural model of the method, and to analyze the structure of the teaching ability of teachers, improve the quality of teaching, strengthen the ability to run schools.
\end{abstract}

\section{Introduction}

Along with our country and the international practice, education plays a more and more role in the play, improve the competitive advantage. In the field of education, teachers are the core part, and teaching is an indispensable part of education, teachers' teaching ability plays a great role in the development of education. According to the characteristics of teachers' teaching ability, the structural model of structural components, and better adapt to the pace of the development of education, to provide practical and effective guidance for the development of colleges and universities.

\section{Characteristics of College Teachers' teaching ability}

Teachers are an integral part of the whole university, and teachers' teaching ability is the basis of the quality of teaching, it is the purpose of higher education, but also to improve the core competitiveness of universities in the form of competition. In the teaching of teachers, each teacher has a certain teaching ability, through the analysis of the characteristics of their ability, summed up the following points:

2.1 Complexity

Teaching is a very complex thing, in teaching, it is easy to unexpected situations, resulting in the process and the results will be changed. In addition, the teaching process involves a lot of content, teachers, students, the relevant teaching content and teaching environment will affect the quality of its teaching. In the process of teaching, it is very easy to be influenced by teachers and students themselves. In order to solve these complex problems, the teaching ability should also have the complexity to improve the quality of teaching.

2.2 Professional

In the cause of education, the professional quality of teachers determines the level of the quality of the nation, which also influences the development of the country and the progress of the national culture. Due to the continuous development of society, the level of science and technology is more and more high, the overall quality of the people also put forward higher requirements. [1] in our country's relevant laws and regulations and strictly the provisions of the teachers' teaching ability must have professional, is a professional with knowledge of the subject is based, also represents a in the field of education to some qualification and level. 


\subsection{Practice}

The scholars believe that the teaching ability of teachers can be reflected through the action, with practical. In the teaching of teachers, there must be a flexible thinking ability, this ability is also known as teaching tact. Teachers in the different teaching environment, will play a different tact of teaching, the teaching tact is not static, teachers can according to actual problem and its creativity, research in the classroom teaching the best teaching mode.

\section{Construction of College Teachers' teaching ability structure model}

If you want to put the real thing, or the phenomenon and the process of imitation, is the model. The structure model is a model of a kind of expression form, can fully reflect the link between a thing the structure features and the causes and effects, a good help to the teaching system is very complicated. The structure model of College Teachers' teaching ability refers to the development and evaluation of teachers' teaching ability. Next, how to build a structure model is proposed:

3.1 The method of constructing the model

In the education industry, there are two ways to construct the teaching ability structure model, one is induction, and one is deductive method. (in this paper, we will use inductive method to construct the structure model of teaching ability of University Teachers) full control to the actual things in, and then through the analysis of the structural elements of things to sort out. Finally, the classification, level, structure analysis, analysis of these elements between the logical connections, and then we can construct a structure model. And the induction method can be divided into analytic hierarchy process and grounded theory, etc.. [2] in these two kinds of construction methods, the deductive method can be used in the analysis of the common structural model, and gradually evolved the teaching ability structure model.

3.2 The steps to construct a structural model

If we want to construct the structure model of College Teachers' teaching ability, we can use the inductive method to realize.

First the literature analysis, and then extract the related elements of the structure, carries on the analysis to the structure of the formation can be explicitly know links between the elements of each structure, through the summary, we can establish the basic logical structure. Finally you can build a structure model of teaching ability of university teachers. After constructing the structure model, the structure model should be analyzed, and the characteristics and the suitable range of the structure are analyzed. At the same time to build the time to continue to modify and improve.

In the structure model of College Teachers' teaching ability, it is divided into four main categories and sixteen sub categories. The four main categories are teaching knowledge, skills, characteristics and social responsibility. The four main categories also have a certain relationship, showing the level of relationship is also a little bit of improvement. In a model of the structure of teaching ability, teaching quality is the most basic requirements, and teaching knowledge is carrying out the teaching of the basic requirements, with teaching skills is the effect is the same, between the two can also help each other; the social responsibility in teaching can force reflects the role is deeper.

\section{Analysis of the structure model of College Teachers' teaching ability}

\subsection{Ability to form dimensions}

Under normal circumstances, if you want to master a skill, the first to start with learning knowledge. And for an activity, the skills are very basic personality traits. In the field of education, knowledge and skills are the main embodiment of teaching ability. Also, and according to the education ability structure model in the onion model analysis, to its point of reasoning, reflected the psychological characteristics of personality, such as attitude, value concept and thinking habit, although reflected the view factors for teaching activities, between the two without direct contact, within a certain period of time to teaching activities arising from the role is not obviously, but in exert a subtle influence on teaching activities produced certain effect and this effect also can not be ignored. 


\subsection{The level of work area}

In the structure model of College Teachers' teaching ability, it can be divided into macro level, meso level and micro level according to the different objectives and the difficulty level.

4.2.1 Macro level

In Colleges and universities of arbitrary a professional prospects for the future and planning ability belong to macro level, and according to the national development plan, on talents, and the students' own characteristics based, then screened for professional training objectives and the specific implementation of the scheme. Through the curriculum system and the teaching activity and so on concrete process can fully improve the student's professional ability. In the application of the model to carry on the teaching, the teacher can take the direction of the country and the research of scientific development into the curriculum, students in the learning of professional knowledge, at the same time, but also continue to improve the comprehensive quality.

\subsubsection{Middle level}

The middle level and the macro level, the embodiment of the function is more specific. In the teaching activities, the ability of the development of any course is included in the middle level. [3] the middle level is to have a certain understanding of the importance of the teaching curriculum, and then according to the importance of design and research for the course objectives, content and evaluation method.

\subsubsection{Micro level}

The micro level is more detailed in the teaching ability structure model. For example, the design of a lesson, the use of related resources, development and evaluation, etc..

4.3 The level of teaching activities

In the teaching of teachers, if you want to make an overall and comprehensive and easy to understand the teaching activities, it is very difficult to understand. If only for a class to be carried out as a basis for the division of teaching activities, then the classification is too detailed, reflecting the value of the classroom. Some scholars to teaching activities are divided three relatively abstract classification, respectively is the form of teaching cognition, operate and monitor, though the terms of classification of too detailed, but when the three classifiers for arbitrary combinations will form completely different teaching activities. Also has the definition that the teaching ability is the teaching quality as well as to the teaching resources development, the utilization foundation. By definition, we can see that the comprehensive and holistic teaching activity is the development and utilization of the relevant resources in the process of learning, so that students can master the knowledge and improve the comprehensive ability.

\section{Summary}

To sum up, through carries on the analysis to the University Teachers' teaching ability structure characteristics to method to construct the structure model of teaching ability of university teachers, and through the ability to form dimension, level in the field of work and teaching level of teaching ability structure model to make the analysis. Only by building a comprehensive and effective teaching ability structure model, teachers can better carry out teaching activities, the school can continue to move forward, to cultivate more talents for the society.

This paper is the research and practice of teaching quality evaluation system of College Teachers' education and teaching reform in Colleges and Universities: a case study of Jiangxi Science \& Technology Normal University as an example. The Topic number of the research: JXJG-15-10-20

\section{References}

[1] Xu Jihong. Study on the structure model of College Teachers' teaching ability [D]. Northeast Normal University, 2013

[2] Hu Hongxia. The structure of technique teachers in College PE teaching ability of [D]. Beijing Sport University, 2007 
[3] Yao Benxian, Yu Chenghai. The structure of College Teachers' teaching ability and its optimization [J]. higher education of agriculture, 2005,12:53-56.

[4] Wang Lijie, Xu Lei, Wu Handong. Study on the structure model of teaching ability of young teachers in Colleges and universities [J]. management and observation, 2014,26:172-173+175. 